\title{
'Hongyi': A New Columnar Ornamental Crabapple
}

\author{
Lulu Zhang, Yijun Yin, Yunfei Mao, Yeping Liu, Huiling Pang, \\ Xiafei Su, Yanli Hu, and Xiang Shen
}

State Key Laboratory for Crop Biology, College of Horticulture Science and Engineering, Shandong Agricultural University, Tai'an, Shandong 271018, China

Additional index words. Malus, columnar tree habit, purple fruit, single petal

Ornamental crabapples (Malus sp.), with their breathtaking display of resplendent blooms in spring and colorful fruit in autumn, are one of the most popular ornamental plants adorning the northern hemisphere (Cronin et al., 2020; Fiala, 1994; Zhang et al., 2020). With the proliferation of flower shapes, colors, and sizes in the market, the breeding of new crabapples has turned to focus on the growing habits and forms of the trees to satisfy the public and private landscapers' desires for different and distinctive varieties (Guan, 2008; Guo et al., 2019; Zhou et al., 2018).

'Hongyi', with its columnar growth habit, bright pink-violet flowers and purple fruit, was selected and released by Shandong Agricultural University to meet this growing market demand. This cultivar has a markedly upright and compact tree shape that stems from its vigorous vertical, but very limited, horizontal growth habit. Of equal significance is its ease of cultivation and low maintenance in annual pruning. 'Hongyi' is particularly suitable for small gardens and use in hedgerows.

\section{Origins}

In mid-Oct. 1999, open-pollinated fruit of 'Red Splendor' growing at Shandong Agricultural University's arboretum were collected and $\approx 1000$ seeds were sown on raised beds at the university's nursery, located in Tai' an, Shandong Province, China (lat. $36^{\circ} 15^{\prime} \mathrm{N}$, long. $117^{\circ} 16^{\prime} \mathrm{E}$ ) the following year. By Spring 2005, 497 young plants had blossomed and yielded fruit.

\section{Propagation and Selection}

Propagation by grafting began in Autumn 2008, using Malus hupeheusis and M. robusta as the rootstocks, and the current year's

Received for publication 17 June 2021. Accepted for publication 13 July 2021.

Published online 5 October 2021.

This project was funded by the Shandong Province Fruit Innovation Team (SDAIT-06-07) and the Shandong Province Industrialization Project of Improved Varieties (2019LZGC007).

We thank Martin Siaw and Ling Guo for advice and editing the manuscript.

$\mathrm{X}$. Shen is the corresponding author. E-mail: shenx@sdau.edu.cn.

This is an open access article distributed under the CC BY-NC-ND license (https://creativecommons. org/licenses/by-nc-nd/4.0/). healthy, plump buds from hardwood branches of the seedlings as the scion. Using growth vigor, pest resistance, and ornamental characteristics as selection criteria in 2011, five outstanding individuals were chosen, including 'Hongyi', which was highly differentiated by its columnar shape and upright crown (Fig. 1).

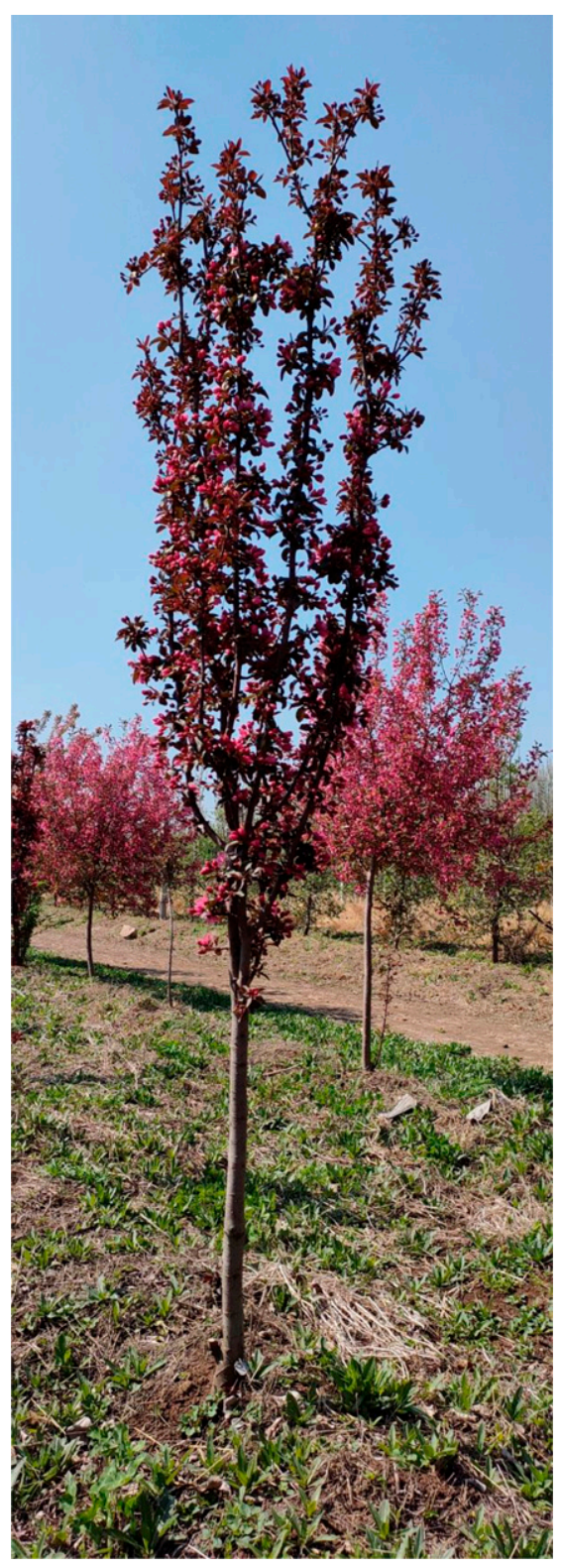

Fig. 1. Growth habit of 'Hongyi'.
'Hongyi' in Chinese characters was so named to reflect its resemblance to a row of tall, sturdy handsome soldiers, where "Hong" encapsulates the color of its blossoms and "Yi" is an expression of its steadfast columnar growth character. In 2015, this new cultivar was accepted by the National Forestry and Grassland Administration of the People's Republic of China and was accorded accession no. 20150052.

\section{Phenotypic Characteristics}

'Hongyi' most closely resembles 'Royalty' and 'Maypole'. We use 'Royalty' and. 'Maypole' as the standards for comparison. Both 'Maypole' and 'Hongyi' exhibit columnar growth habits, whereas 'Royalty' is upright. The flowers of 'Hongyi' differ from those of 'Royalty' and 'Maypole' in color. The middle zone of the inner side of 'Hongyi' is dark pink-violet [Royal Horticultural Society (RHS)-80D] (Royal Horticultural Society, 2007), that of 'Royalty' is purple (RHSN71A), and 'Maypole' is red-purple (RHSN61B). The young leaves of 'Hongyi' and 'Royalty' are dark brown, whereas 'Maypole' is dark pink-violet (RHS-N77A). In addition, the fruit color of 'Hongyi' is purple (RHS-58A) in autumn, whereas the fruit color of 'Royalty' is purple-brown (RHS-183A), and the fruit color of 'Maypole' is orange-red (RHS-N34A) (Table 1).

The physiological characteristics of 'Hongyi' described in the following paragraphs are in accordance with the guidelines specified for ornamental apples by the International Union for the Preservation of New Varieties of Plants (2003). The specific characteristics of 'Hongyi' are shown in Table 1.

Habit. Young shoots are dark pink-violet (RHS-N77A), with purple-brown (RHS183A) perennial branches (Table 1). Almost all the buds of 1-year-old shoots developed into spurs with strong flowering abilities. The cultivar has an upright trunk, a columnar crown measuring $50 \mathrm{~cm}$, and reaches a height of $3.6 \mathrm{~m}$ after 4 years of growth. It exhibits strong vertical, but weak lateral, growth (Fig. 1), and its crown-to-diameter ratio reaches 7.2.

Foliage. The young leaves are dark brown (RHS-200B) (Fig. 2, Table 1), with petioles measuring between 2.9 and $3.4 \mathrm{~cm}$, whereas the mature leaves are dark green with a leathery texture. The shape of the leaves is broad elliptic (between 10.2 and $11.7 \mathrm{~cm}$ in length, and $6.5-6.9 \mathrm{~cm}$ in width, with a length-towidth ratio of 1.5-1.7) with sharply cuspidate tips, a broadly circular base, and prominent venation. The leaves also have crenate margins, but without lobes. The leaf surfaces have a fold with an upright leaf posture.

Flowers. Short branches have a strong ability to form flowers continuously. Flower buds are dark pink-violet (RHS-N77B), and each inflorescence has four to six flowers. The flowers have single, oblong-ovoid petals with blunt tips, measuring between 4.4 and $5.4 \mathrm{~cm}$ in diameter, and bloom in a flattened, horizontal position. The basal zone of the inner side is white (RHS-N999D), whereas 
Table 1. Comparison of phenotypic attributes between three crabapple cultivars with similar appearances and characteristics: 'Hongyi', 'Royalty', and 'Maypole'.

\begin{tabular}{|c|c|c|c|}
\hline Comparison items & Hongyi & Royalty & Maypole \\
\hline Growth habit & Columnar & Upright & Columnar \\
\hline New shoot color & Dark pink-violet (RHS-N77A) & Purple (RHS-N79C) & Dark pink-violet (RHS-N77A \\
\hline Perennial branch color & Purple-brown (RHS-183A) & Blue gray (RHS-188A) & Gray (RHS-201A) \\
\hline Expanding young leaf, blade color & Dark brown (RHS-200B) & Dark brown (RHS-200A) & Dark pink-violet (RHS-N77A) \\
\hline Time of beginning of flowering ( $10 \%$ open flowers) & Late & Medium & Late \\
\hline Petal color of the middle zone of the inner side & Dark pink-violet (RHS-80D) & Purple (RHS-N71A) & Red-purple (RHS-N61B) \\
\hline Petal color of the marginal zone of the inner side & Pink-violet (RHS-N75C) & Purple (RHS-N71A) & Red-purple (RHS-N61B) \\
\hline Petal color of the basal zone of the inner side & White (RHS-N999D) & Dark pink (RHS-N61C) & Red-purple (RHS-N61B) \\
\hline Flower diameter $(\mathrm{cm})$ & $4.5-5.4$ & $4.3-5.3$ & $5.2-5.8$ \\
\hline Fruit predominant color & Purple (RHS-58A) & Purple-brown (RHS-183A) & Orange-red (RHS-N34A) \\
\hline
\end{tabular}

RHS = Royal Horticultural Society (2007).

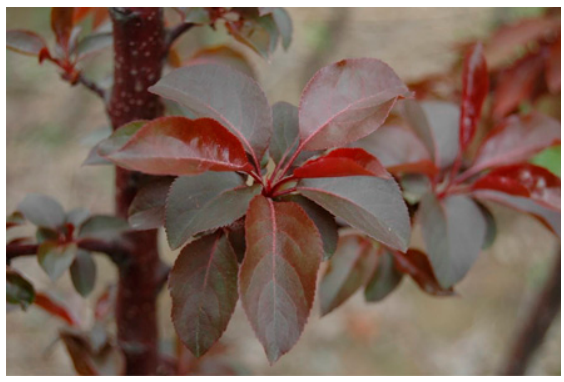

Fig. 2. Newly sprouted leaves of 'Hongyi'.

the color of the marginal zone of the inner side of the petal is pink-violet (RHS-75C) (Table 1). The middle zone of the inner side is dark pink-violet (RHS-80D) and the outer side is a dark pink-violet (RHS-N77B) (Table 1). The stamens are between 0.7 and $1.1 \mathrm{~cm}$ long, with pink filaments and dark-red filigrees. The pistils, measuring between 1.1 and $1.3 \mathrm{~cm}$, are pink with a modest amount of white pubescence. The pedicels are deep ruby in color, slender in shape, measuring between 2.9 and $3.2 \mathrm{~cm}$ in length, and have no pubescence. The calyx is triangular with sharply cuspidate tips, measuring between 0.65 and $0.73 \mathrm{~cm}$ in length. It has sparsely glandular dentate margins and pubescence (Fig. 3).

Fruit. The fruit mature into a rich purple color (RHS-58A), with highly visible white powder on the surface of the peel (Table 1). They are oblong and sunken at both ends, with the average vertical diameter measuring $1.5 \mathrm{~cm}$ and average horizontal diameter measuring $2.0 \mathrm{~cm}$. (Fig. 4).

\section{Cultivation}

'Hongyi' has demonstrated strong adaptability and is suitable for cultivation where

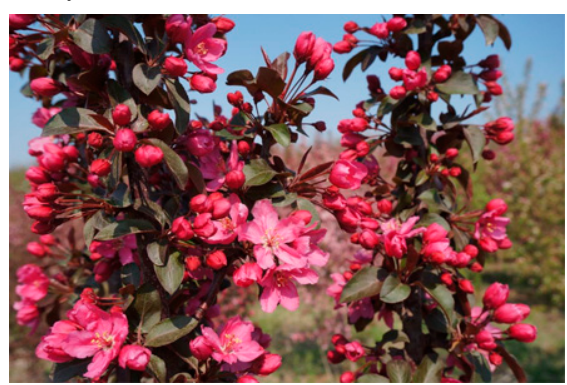

Fig. 3. Flowering in 'Hongyi'.

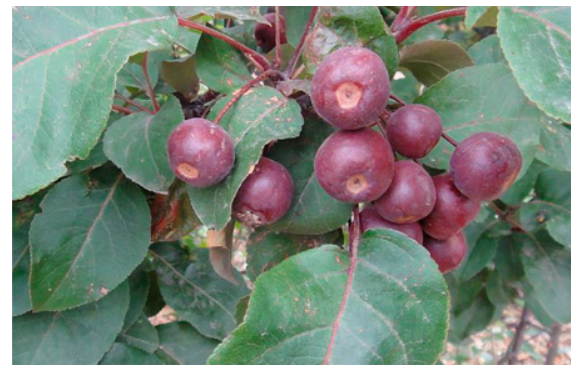

Fig. 4. Fruit characteristics of 'Hongyi'.

apples are grown: in the north, east, and northwest areas of China, corresponding with U.S. Department of Agriculture cold hardiness zones 5 through 9 (Daly et al., 2012; McKenney et al., 2006). Likewise, 'Hongyi' can be widely grown in Europe, wherever apples are grown, as well (Laurens et al., 2018; Legave et al., 2013, 2015).

The planting location should be as far away as possible from any Juniperus sabina plants to avoid being affected by rust diseases ( $\mathrm{Li}$ et al., 2008; Shen and Ma, 2019). The plants should be monitored and treated if needed in the summer months to control the emergence and growth of apple aphids and spider mite (Deng et al., 1993; Jia et al., 2004; Xu, 2002).

Sufficient basal fertilizer should be put in place before planting. Two months after planting, according to the nutrient requirement of the tree, it should be judged whether to apply additional compound fertilizers to the seedlings to promote the robust and healthy formation of the trees (Milosevic et al., 2019; Rose, 1999; Rose et al., 1999; Stoven et al., 2006). According to the nutrient demand of fruit trees and the environmental benefit characteristics of fertilization at this stage, we can judge whether to add compound fertilizer with different components before or after flowering to promote the normal development of flowers and fruit (Ge et al., 2017; Neilsen et al., 2001).

\section{Pruning and Landscape Application}

This cultivar has an upright posture and strong branching habit with many short horizontal branches. Because the tree is columnar and has limited lateral expansion, no pruning is generally required except to maintain a desired height.
Its compact growth habit lends itself to be widely used in small gardens (Yanny, 1991). Similarly, its tall, architectural shape makes it an ideal choice for creating visually striking row plantings (Linden et al., 2009; Liu et al., 2012).

\section{Availability}

Malus 'Hongyi' is available from Shandong Agricultural University (Tai'an, Shandong Province, China). Please direct all inquiries to Xiang Shen (e-mail: shenx@sdau.edu.cn).

\section{Literature Cited}

Cronin, D., P. Kron, and B.C. Husband. 2020. The origins and evolutionary history of feral apples in southern Canada. Mol. Ecol. 29(10): 1776-1790, https://doi.org/10.1111/mec.15277.

Daly, C., M.P. Widrlechner, M.D. Halbleib, J.I. Smith, and W.P. Gibson. 2012. Development of a new USDA plant hardiness zone map for the United States. J. Appl. Meteorol. Climatol. 51(2):242-264, https://doi.org/10.1175/2010JA MC2536.1.

Deng, J.Q., G.S. Rui, Y.T. Guan, Y.Q. Yu, D.M. Zhang, and J.Y. Hong. 1993. The selection of an apple stock line, Siberian crabapple Jin 67, immune to the woolly apple aphid. Acta Phytophylacica Sin. 20(3):217-222, https://doi.org/ 10.13802/j.cnki.zwbhxb.1993.03.006.

Fiala, J.L. 1994. Flowering crabapples: The genus Malus. Timber Press, Portland, OR.

Ge, S.F., Z.L. Zhu, S.C. Wei, and Y.M. Jiang. 2017. Technical approach and research prospect of saving and improving efficiency of chemical fertilizers for apple in China. Acta Hortic. Sin. 44(09):1681-1692, https://doi.org/ 10.16420/j.issn.0513-353x.2017-0382.

Guan, C.Y. 2008. Study on the cultivation history and cultural significance of chinese flowering crabapple. Ancient Modern Agr. 02:67-74, https:// doi.org/10.3969/j.issn.1672-2787.2008.02.009.

Guo, L., Y. Cao, J. Quan, and B.Y. Liu. 2019. Crabapple in China: Past, present and future. Acta Hort. 1263:55-60, https://doi.org/10.17660/ ActaHortic.2019.1263.6.

International Union for the Preservation of New Varieties of Plants. 2003. Guidelines for the conduct of tests for distinctness, uniformity and stability [ornamental apple (Malus Mill.) TG/192/ 1]. International Union for the Preservation of New Varieties of Plants, Geneva, Switzerland.

Jia, Z., Z.W. Song, Z.Y. Jin, and L. Wang. 2004. Studies on the POD activities in pearleaf crabapple (Malus zumi) leaves damaged by plum spider mite (Tetranychus viennensis). Acta Bot. Boreal.- 
Occident. Sin. 24(11):2136-2139, https://doi.org/ 10.3321/j.issn:1000-4025.2004.11.030.

Laurens, F., M.J. Aranzana, P. Arus, D. Bassi, M. Bink, J. Bonany, A. Caprera, L. Corelli-Grappadelli, E. Costes, C.E. Durel, J.B. Mauroux, H. Muranty, N. Nazzicari, T. Pascal, A. Patocchi, A. Peil, B. Quilot-Turion, L. Rossini, A. Stella, M. Troggio, R. Velasco, and E. van de Weg. 2018. An integrated approach for increasing breeding efficiency in apple and peach in Europe. Hort. Res. 5(1):11, https:// doi.org/10.1038/s41438-018-0016-3.

Legave, J.M., M. Blanke, D. Christen, D. Giovannini, V. Mathieu, and R. Oger. 2013. A comprehensive overview of the spatial and temporal variability of apple bud dormancy release and blooming phenology in western Europe. Intl. J. Biometeorol. 57(2):317-331, https://doi.org/10.1007/s00484-0120579-x.

Legave, J.M., Y. Guédon, G. Malagi, A. El Yaacoubi, and M. Bonhomme. 2015. Differentiated responses of apple tree floral phenology to global warming in contrasting climatic regions. Front. Plant Sci. 6:1054, https://doi.org/10.3389/fpls.2015.01054.

Li, Z., X. Wang, and D.L. Wang. 2008. First report of rust disease caused by Puccinia elymi on Leymus chinensis in China. Plant Pathol. 57(2):376, https://doi.org/10.1111/j.1365-3059.2007.01675.x.

Linden, L., L. Hauta-aho, O. Temmes, and S. Tegel. 2009. An inventory of old lilac and crab apple cultivars in the city of Helsinki, Finland. Acta Hort. 881:1027-1030, https://doi.org/ 10.17660/ActaHortic.2010.881.171.
Liu, Y., W.C. Huang, and G.P. Peng. 2012. Current status of crabapple garden in Chenshan Botanical Garden and its development suggestions. J. South. Agr. 43(6):835-838.

McKenney, D.W., M.H. Pia Papadopol, K. Campbell, and K. Lawrence. 2006. The generation of USDA-equivalent extreme minimum temperature models and a comparison with Canada's plant hardiness zones. Can. J. Plant Sci. 86(2):511-523, https://doi.org/10.4141/p05-070.

Milosevic, T., N. Milosevic, and J. Mladenovic. 2019. Tree vigor, yield, fruit quality, and antioxidant capacity of apple (Malus $\times$ domestica Borkh.) influenced by different fertilization regimes: Preliminary results. Turk. J. Agr. For. 43(1): 48-57, https://doi.org/10.3906/tar-1803-109.

Neilsen, D., P. Millard, L.C. Herbert, G.H. Neilsen, E.J. Hogue, P. Parchomchuk, and B.J. Zebarth. 2001. Remobilization and uptake of $\mathrm{N}$ by newly planted apple (Malus domestica) trees in response to irrigation method and timing of $\mathrm{N}$ application. Tree Physiol. 21(8):513-521, https://doi. org/10.1093/treephys/21.8.513.

Rose, M.A. 1999. Nutrient use patterns in woody perennials: Implications for increasing fertilizer efficiency in field-grown and landscape ornamentals. HortTechnology 9:613-617, https:// doi.org/10.21273/HORTTECH.9.4.613.

Rose, M.A., M. Rose, and H. Wang. 1999. Fertilizer concentration and moisture tension affect growth and foliar $\mathrm{N}, \mathrm{P}$, and $\mathrm{K}$ contents of two woody ornamentals. HortScience 34:246-250, https://doi.org/10.1016/j.jpowsour.2004.02.034.
Royal Horticultural Society. 2007. RHS colour chart. 5th ed. Royal Horticultural Society, London, UK.

Shen, Y. and G. Ma. 2019. Occurrence regularity and ecological control technology of diseases of hedgerow commonly used in greening in five cities of southern Jiangsu. J. Landscape Res. 11(6):141-144, https://doi.org/10.16785/j. issn1943-989x.2019.6.033.

Stoven, A.A., H.M. Mathers, and D.K. Struve. 2006. Fertilizer application method affects growth, nutrient, and water use efficiency of container-grown shade tree whips. HortScience 41:1206-1212, https://doi.org/10.21273/hortsci. 41.5.1206.

Xu, L.D. 2002. Development and reproduction of hawthorn spider mites on apple cultivars. Entomol. Knowl. 39(5):350-352, https://doi.org/ 10.3969/j.issn.0452-8255.2002.05.007.

Yanny, M. 1991. The shy yet elegant crabapple: 'Blanche Ames'. Arnoldia 51(1):33-37, https:// doi.org/10.2307/42955348.

Zhang, L.L., Y.F. Mao, Y.Y. Wang, L. Yang, Y.J. Yin, C.H. Zhang, D.J. Zhang, and X. Shen. 2020. Malus spectabilis 'Duojiao': A new yellow-leaf cultivar. HortScience 55:1155-1158, https://doi.org/10.21273/HORTSCI14865-20.

Zhou, T., X.C. Shen, D.J. Zhou, J.J. Fan, M.M Zhao, W.X. Zhang, and F.L. Cao. 2018. Advances in the classification of crabapple cultivars. Acta Hort. Sin. 45(2):380-396, https:// doi.org/10.16420/j.issn.0513-353x.2017-0140. 